\title{
Hvordan sikrer jeg, at publiceringsdatoen er korrekt?
}

I forbindelse med tildeling af DOI til de enkelte artikler er det vigtigt, at publiceringsdatoen er korrekt, ellers kan man risikere, at en artikel udgivet i f.eks. 2002 rent faktisk står som udgivet i 2015. Noget, der minder om en situation, der opstod da en online-musiktjeneste anførte, at Beatles havde udgivet al deres musik efter år 2000 og altså ikke i 60’erne. Fejlen opstår typisk, når man publicerer tidligere numre (back issues). Hvis man ikke selv registrerer publiceringsåret vælger programmet automatisk dags dato. Fejlinformationen kan også opstå, hvis man anvender QuickSubmit-publiceringsmetoden og ikke husker at registrere publiceringstidspunktet.

Men fejlen er let at rette. Man logger ind på sit tidsskrift som redaktør og klikker på "Tidligere numre"

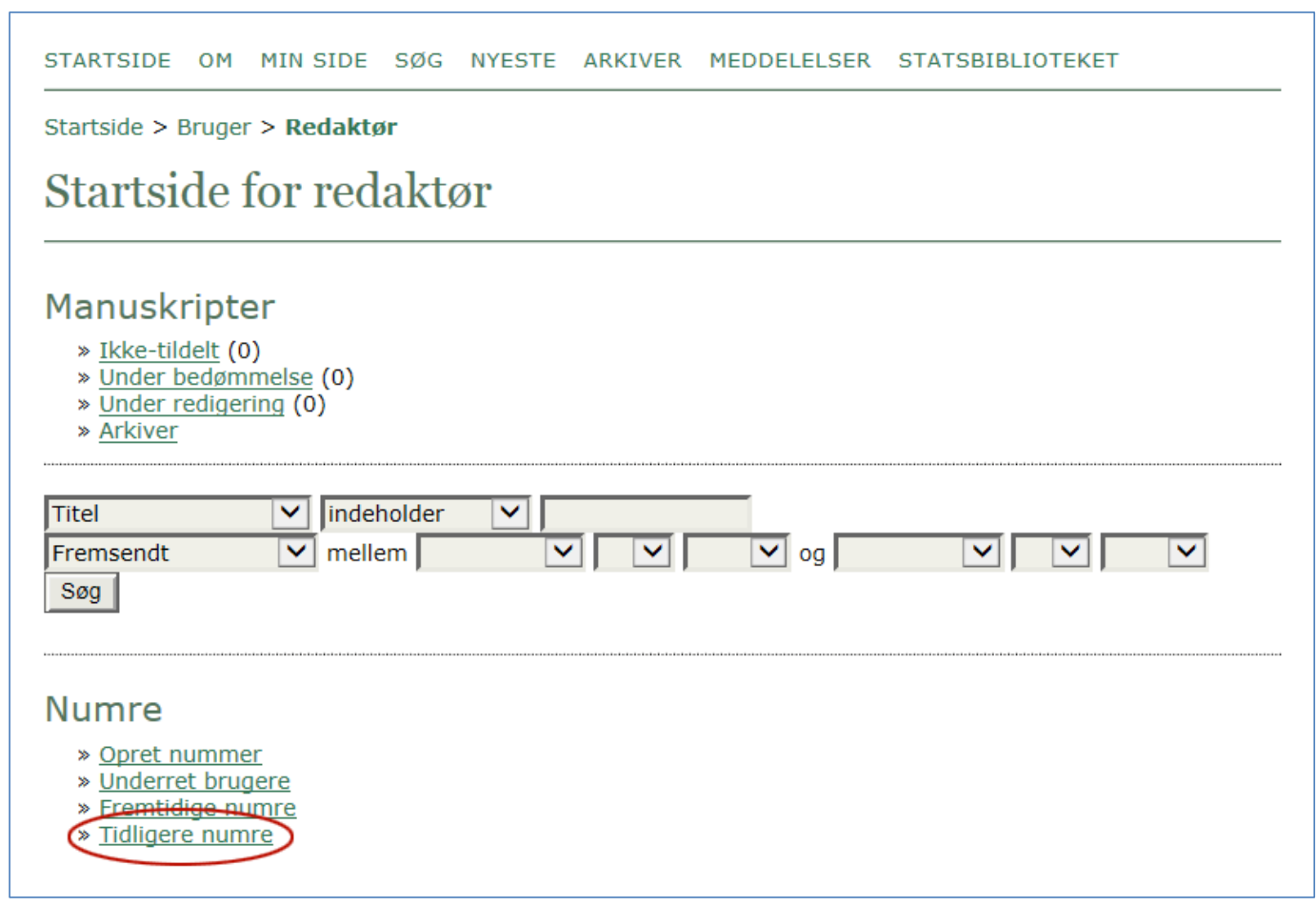

Her får du en liste over udgivne numre. Du klikker så på det nummer, du ønsker at tilrette

\begin{tabular}{|c|c|c|c|c|}
\hline \multicolumn{5}{|c|}{$\begin{array}{l}\text { OPRET NUMMER FREMTIDIGE NUMRE TIDLIGERE NUMRE } \\
\text { Dette tidsskrift anvender brugerdefineret nummersortering. NULSTIL TIL STANDARDER }\end{array}$} \\
\hline NUMMER & PUBLICERET & ARTIKLER & REKKEFøLGE & HANDLING \\
\hline 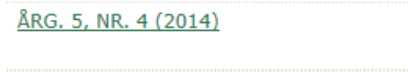 & $\begin{array}{l}2014-12- \\
19\end{array}$ & 7 & 11 & $\underline{\text { SLET }}$ \\
\hline 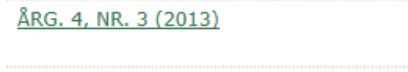 & $\begin{array}{l}2013-12- \\
06\end{array}$ & 6 & $1 \perp$ & SLET \\
\hline 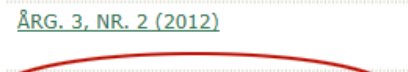 & $\begin{array}{l}2012-08- \\
28\end{array}$ & 7 & $1 \perp$ & $\underline{\text { SLET }}$ \\
\hline ARG. 1, NR. 1 (2010): VELKOMMEN & $\begin{array}{l}2010-09- \\
07\end{array}$ & 14 & 11 & $\underline{\text { SLET }}$ \\
\hline
\end{tabular}


Her bliver du præsenteret for en liste over artiklerne.

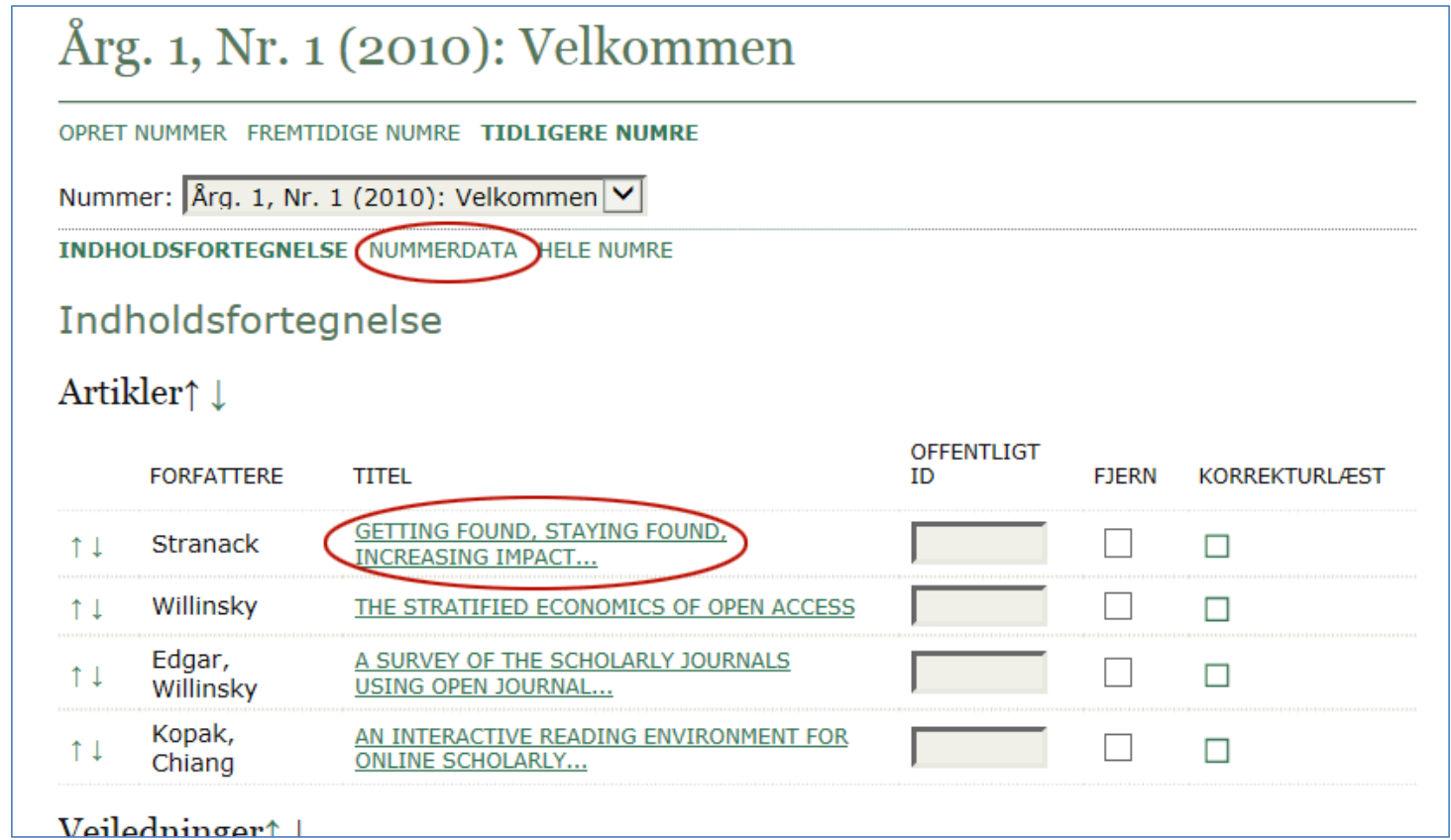

Hvis det er selve nummeret, der skal have ændret publiceringsdato, skal du klikke på Nummerdata. Hvis det er artiklen, skal du klikke på linket under "Titel", hvorefter du kan rette data der.

Klikker du på Nummerdata, får du adgang til følgende side.

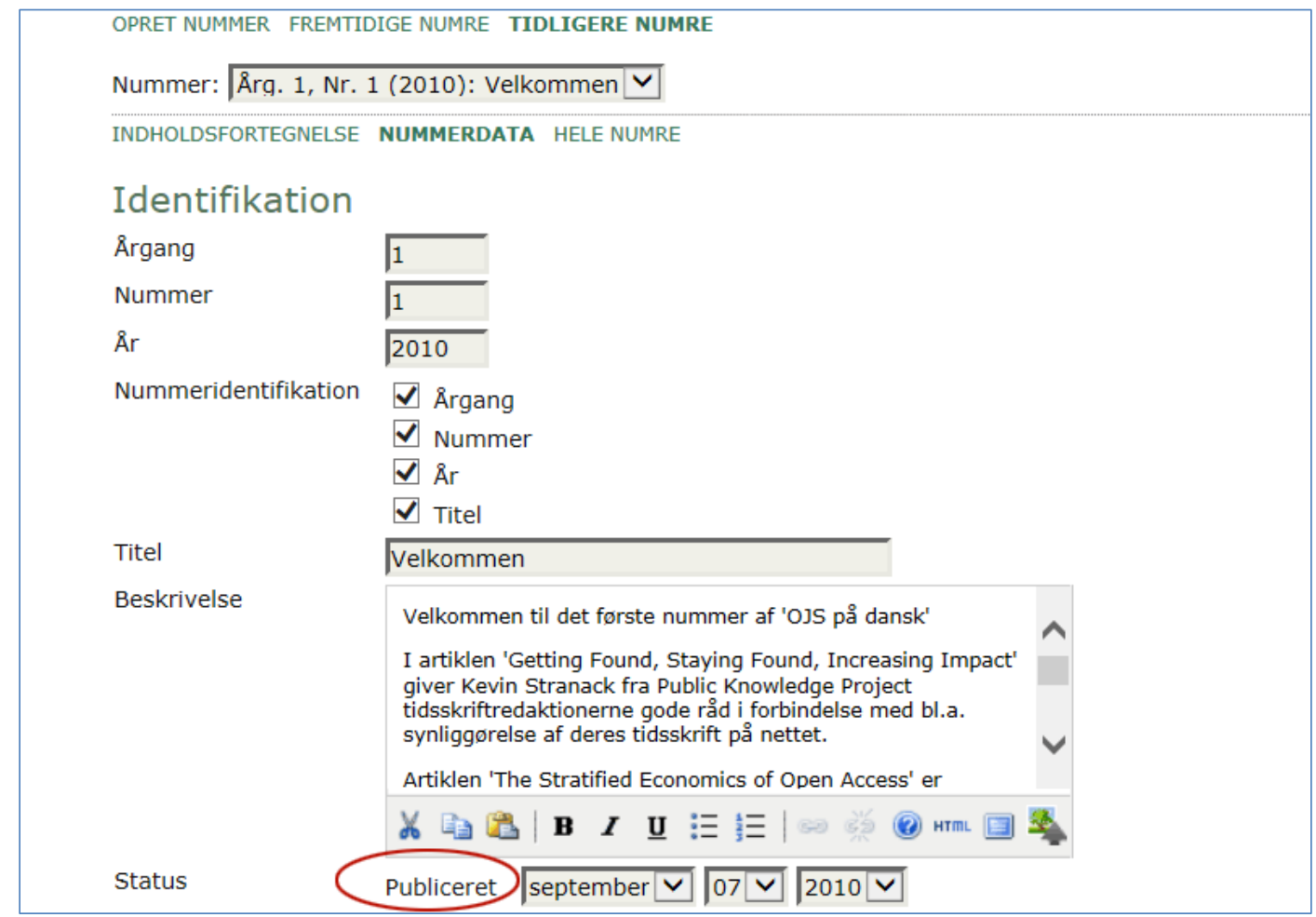

Her retter du datoen og klikker "Gem" nederst på siden. 
Når du klikker på oplysningerne om den enkelte artikel, får du Resumé-siden. Her skal du vælge linket "Redigering"

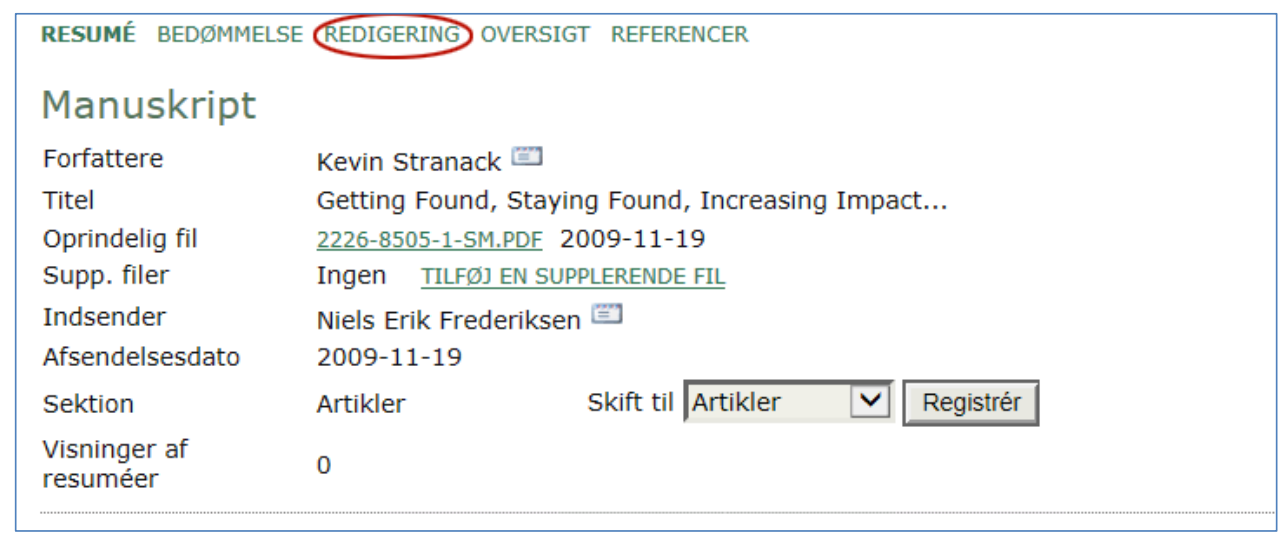

På redigeringssiden skal du gå ned til "Publiceret" og indsætte den rigtige dato. Klik derefter på "Registrér". Er der tale om en artikel, der er udgivet for lang tid siden, skal du klikke på pilen ved siden af årstallet og vælge det tidligste årstal. Systemet går kun 10 år tilbage for hver gang du klikker på registrér, så denne proces skal gentages indtil du er nået tilbage til det relevante årstal. Når du er færdig, skal du klikke på "Indholdsfortegnelse", hvorefter du ryger tilbage til det pågældende nummers indholdsfortegnelse, hvorfra du kan gentage processen, indtil alle artikler har de korrekte oplysninger vedhæftede.

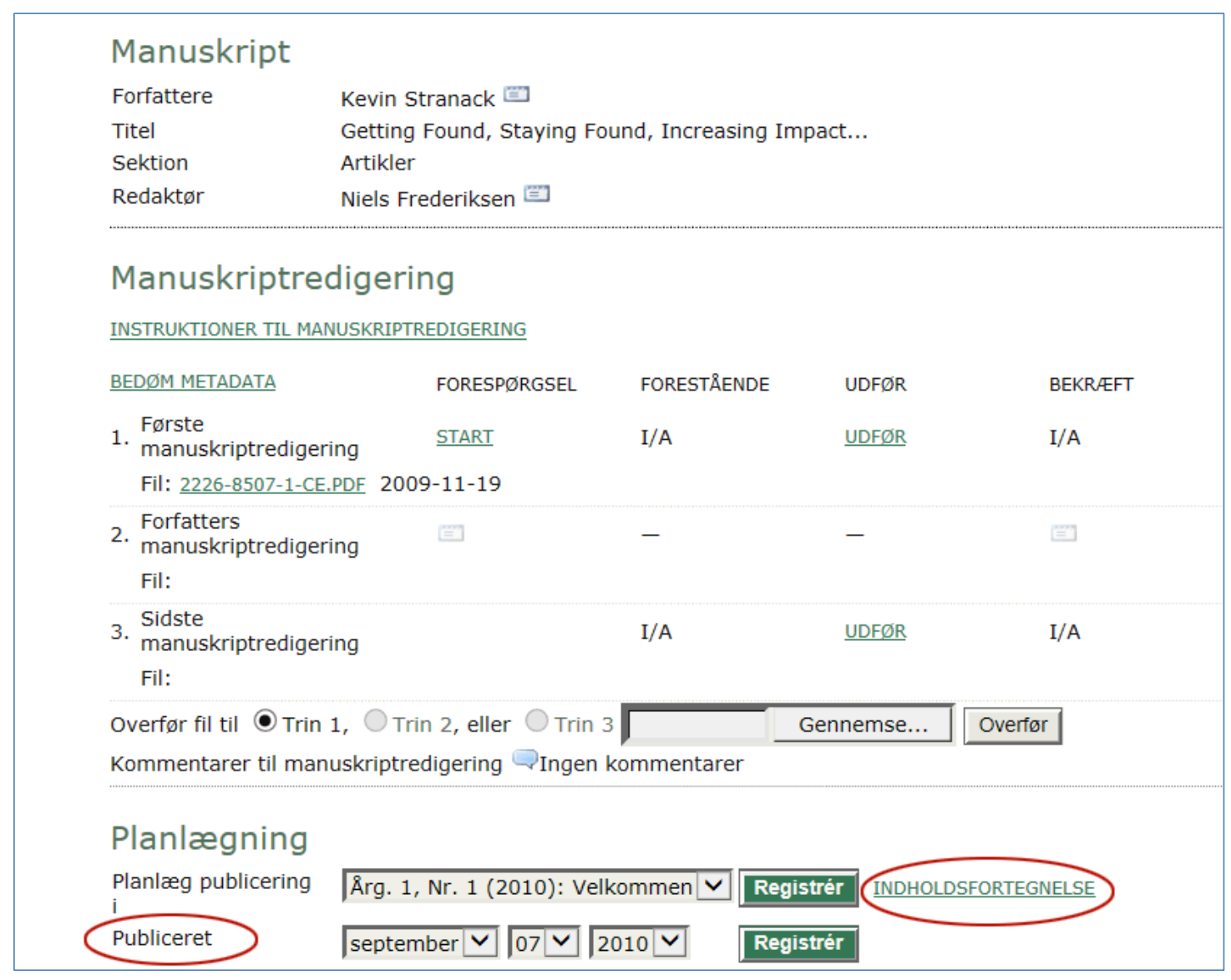

Jesper Boserup Thestrup og Niels Erik Frederiksen, marts 2015 